\title{
MARTIN HEIDEGGER E O JOVEM LETÃO: OUTRA VEZ A QUESTÃO POLÍTICA *
}

\author{
José Reinaldo F. Martins Filho **
}

\section{$\S 1$. Do ponto de partida e dos autores relacionados}

Neste breve relato biobibliográfico, gostaria de deixar registrada uma relação que, até muito recentemente, permanecia completamente ignorada por mim (e, imagino, também por muitos). De minha parte, sua explicitação levou a pensar como são compostos os nossos próprios itinerários, muitas vezes interrelacionados ao de identidades anônimas, mas cuja influência demonstra-se crucial para a consecução de determinados desfechos, de reviravoltas históricas, como alento ou consequência, mas sempre como amálgama de uma passagem. Os dois autores aos quais farei alusão tiveram suas vidas aproximadas no curso de um evento epocal. Cada qual movido por suas contingências específicas, unidos no que ficaria conhecido como um dos episódios mais dramáticos do passado recente: a II Guerra Mundial. O primeiro, dispensa apresentações, contando com uma influência que ultrapassa os limites da filosofia. O segundo, embora menos conhecido do grande público, é um dos mais importantes herpetologistas do continente

\footnotetext{
* Agradeço a todos os que direta ou indiretamente estão envolvidos no texto que segue, especialmente aos professores Janis Arnold Roze, que nos deu o ensejo para essa discussão, e Friedrich-Wilhelm von Herrmann, pela constante interlocução.

** Professor efetivo do Programa de Pós-Graduação em Ciências da Religião da Pontifícia Universidade Católica de Goiás. Coordenador do Bacharelado em Filosofia do Instituto de Filosofia e Teologia de Goiás (IFITEG). Atualmente desenvolve estágio de Pós-Doutorado em Teologia, com bolsa CNPq (PDJ), junto à Pontifícia Universidade Católica do Rio de Janeiro. Tem formação nas áreas de Filosofia, Teologia e Música. E-mail: jreinaldomartins@gmail.com
} 
americano, fundador, professor e diretor emérito do Museu Americano de História Natural, ligado à City University of New York. Quando do episódio que será narrado, o primeiro já gozava de reconhecimento público e se via envolto na querela de seu envolvimento partidário com o Nacional Socialismo na Alemanha. O segundo, ainda muito jovem, arriscava a vida como alistado voluntário junto às forças de coalisão, que acabavam de ter vencido a guerra e, por isso, permaneciam em território alemão. Para além do relato por si mesmo - uma eventualidade do destino, ou simples acaso -, enxergamo-lo como mais uma oportunidade para tratar a questão política de Heidegger, sobretudo face aos novos desdobramentos postos em curso nos últimos anos. Eis porque começaremos por isso.

\section{§ 2. Pressupostos relativos à questão política de Heidegger}

Especialmente desde que assumiu o cargo de Reitor da Universidade de Freiburg, do qual resolveu afastar-se após um período de dez meses (de abril de 1933 a fevereiro de 1934), a relação entre Heidegger e o Nazismo tem se mostrado um tema que desperta interesse de um grande público especializado ou não -, sendo interpretada das mais diferentes maneiras. Há, nesse sentido, os que defendem desde uma mera inabilidade política prática por parte do autor, até, ao contrário, aqueles que advogam um compromisso velado e obscuro presente nalguns dos principais pontos do pensamento heideggeriano, tendo nisso sintonia com o ideário nacional-socialista. Passado o período de guerra, essa querela estendeu-se à posteridade, recentemente reacendida pela publicação dos chamados Schwarze Hefte, isto é, os cadernos de capa preta em que Heidegger frequentemente realizava suas anotações - geralmente relativas à composição de seu pensamento, mas também com sugestões de caráter prático, lembranças e impressões da vida em geral. A publicação desse material despertou um verdadeiro frenesi na imprensa europeia, fomentando debates "prós" e "contra" a "contaminação nazista" do pensamento de Heidegger.

Isso porque as impressões de agora vieram do próprio editor dessa parte das obras completas do filósofo (Gesamtausgabe), Peter Trawny. Em 2014, logo após a divulgação dos primeiros tomos dos Schwarze Hefte que vieram a público, Trawny lançou um pequeno livro, titulado Heidegger e o mito da conspiração judaica mundial (no Brasil a tradução saiu no ano imediatamente seguinte, em $2015^{1}$ ). Embora pouco paginoso, o livro é suficiente para demonstrar a hipótese de Trawny de que haveria um antissemitismo onto-histórico inerente ao pensamento heideggeriano de maneira mais abrangente, sobretudo caso as passagens da sua filosofia fossem contrastadas com

\footnotetext{
${ }^{1}$ Cf. TRAWNY, Peter. Heidegger e o mito da conspiração judaica mundial. Tradução de Soraya Guimarães Hoepfner. Rio de Janeiro: Mauad X, 2015.
} 
o testemunho colhido das anotações ora disponíveis. Foi justamente isso que o editor dos Schwarze Hefte pretendeu realizar, ignorando a advertência de Heidegger de que os editores de seus textos não se encarregassem de também interpretá-los imediatamente à sua publicação, evitando estabelecer a hipótese de uma linha exegética supostamente "correta" a despeito de outras - e voltaremos a isso mais adiante.

Pensando a realidade brasileira, contexto a partir do qual nos inclinamos ao tratamento do tema, reforçando o caráter de imputação antissemita a Heidegger, a editora É Realizações reeditou o livro de Victor Farías, um dos mais radicais entre os que já fomentaram esse debate. Reportando-se ao material originalmente publicado em 1987, a edição de 2017 passou a incluir o que seria a herança maléfica de Heidegger também passível de apreensão em fenômenos como o radicalismo islâmico ou a ascensão das esquerdas radicais na América Latina ao longo das últimas décadas². Como se não bastassem os argumentos do próprio Victor Farías, na apresentação da obra o escritor convidado reivindica uma espécie de "co-responsabilidade" nociva às demais filosofias que beberam de Heidegger, ou, mesmo, aos pesquisadores cuja vida fora de algum modo dedicada à compreensão e explicitação do pensamento heideggeriano e de seu legado como um todo - no caso brasileiro, isso incluiria, entre tantos outros, Ernildo Stein, João Mac Dowell, Zeljko Loparic ou Benedito Nunes, esse já de feliz memória.

É certo que toda essa polêmica chegou a ser tratada pelo próprio Heidegger, por exemplo, na entrevista concedida à revista alemã Der Spiegel, em setembro de 1966. Por indicação expressa do filósofo o material obtido apenas poderia ser publicado após a sua morte, ocorrida em 26 de maio de 1976. Assim, seu conteúdo apareceu no número 23 da revista em 1976 (31 de maio). Antes do material resultante da entrevista, uma nota justificava a publicação: Heidegger havia se dirigido ao Der Spiegel em março de 1966, através de uma carta, em que desmentia alguns dos dizeres geralmente imputados a ele no tocante à sua conduta durante o Terceiro Reich. Especialmente por conta do silêncio do autor a respeito do tema ao longo de três décadas, os editores Rudolf Augstein e Georg Wolff resolveram agendar uma entrevista, a qual se deu no mês de setembro imediatamente seguinte. Ao longo de toda a entrevista, duas coisas parecem ficar evidentes: em primeiro lugar, que seu cerne corresponderia à tênue e ainda cabalmente inexplorada relação de Heidegger com o nazismo; por conseguinte, que muitos dos comentários geralmente tomados como legítimos sobre esse envolvimento eram, na verdade, "meias verdades", ou, até, como chamou o filósofo, "calúnias difamatórias" ${ }^{3}$. Aliás, há nesse sentido bastante simi-

\footnotetext{
${ }^{2}$ FARIAS, Victor. Heidegger e sua herança: o neonazismo, o neofascismo e o fundamentalismo islâmico. Tradução de Antônio Fernando Souza Borges. São Paulo: É Realizações, 2017.

${ }^{3}$ HEIDEGGER, Martin. „Gespräch mit Martin Heidegger am 23. September 1966“. In. Der Spiegel, n. 23, 1976. p. 193-219.
} 
laridade entre algumas afirmações dadas à entrevista e trechos vindos à tona com a publicação dos Schwarze Hefte, como, à guisa de ilustração, suas referências à relação com Husserl: "Nunca fiz nada contra Husserl. Mente-se quando se diz que o expulsei da universidade e que lhe vetei o acesso à biblioteca. Desde 1928 Husserl ficara emérito por seu próprio pedido; desde então não mais ofereceu cursos ou exercícios; não mais usou a biblioteca da universidade" ${ }^{\prime 4}$.

Até a divulgação da entrevista, além disso, não se falava com clareza sobre a causa da demissão de Heidegger do reitorado da Universidade de Freiburg, em fevereiro de 1934. Ao recusar-se a demitir os decanos das faculdades que eram de origem judia, por ele próprio empossados no início daquele ano (entre os quais o seu predecessor como reitor e amigo, o qual em grande parte foi o responsável por seu aceite ao cargo, o professor Möllendorf, da Faculdade de Medicina ${ }^{5}$ ), Heidegger teve sua cabeça a prêmio. Em uma das questões da entrevista, em que esse episódio é mencionado, o filósofo chega a reclamar que enquanto a imprensa de dentro e de fora do país comentou de diversas maneiras seu aceite ao reitorado, não disse uma sequer palavra sobre sua demissão ${ }^{6}$. Além dessa informação, outras supostas ações do então reitor puderam ser contrapostas à sua própria palavra, como a referida proibição de Husserl de frequentar a biblioteca da Universidade, ou a queima de livros de autores judeus, ou, ainda, a obrigação de estampar os cartazes antissemitas no perímetro da Instituição, todos negados por Heidegger na entrevista.

Enfim, como atualmente é sabido por diferentes fontes, passados os meses de reitorado, o relacionamento de Heidegger com o partido Nacional Socialista apenas piorou. Sobre isso, se da parte da leitura impetrada pela posteridade a aproximação de Heidegger com o nazismo nunca seria completamente justificada/perdoada - especialmente após a descoberta de todos os desdobramentos do governo de Hitler - também por parte dos próprios membros do partido o filósofo nunca chegou a ser uma figura bem-querida e de confiança. Entre outros aspectos, o biógrafo Rüdiger Safranski ${ }^{7}$ destaca a não participação de Heidegger no Congresso Internacional de Filosofia de Praga, em 1934 e, mesmo, no Congresso Internacional

\footnotetext{
${ }^{4}$ HEIDEGGER, Anmerkungen V, S, p. 462-463. In. ALFIERI, Francesco; von HERRMANN, Friedrich-Wilhelm. Martin Heidegger: la veritá sui Quaderni neri. Brescia: Editrice Morceliana, 2016. p. 283.

${ }^{5}$ HEIDEGGER, Martin. „Gespräch mit Martin Heidegger am 23. September 1966“. In. Der Spiegel, n. 23, 1976. p. 196

${ }^{6}$ HEIDEGGER, Martin. „Gespräch mit Martin Heidegger am 23. September 1966“. In. Der Spiegel, n. 23, 1976. p. 196.

7 SAFRANSKI, Rüdiger. Ein Meister aus Deutschland: Heidegger und seine Zeit. München: Carl Hanser Verlag, 1994.
} 
de Paris, em 1937, como demonstrações de que o autor realmente não era tomado como confiável pelas forças do führer. Tais episódios também são mencionados na entrevista ao periódico Der Spiegel ${ }^{8}$. Conforme confessa Heidegger, a direção do evento francês chegou a interpelar o Ministério da Educação do Reich, questionando sobre a sua não inclusão na delegação alemã. Como consequência, tentaram incluí-lo de última hora, através de uma ligação do governo de Berlim, convite que foi recusado, como forma de repúdio ao tratamento prestado.

Outro indicativo de que por parte do partido o filósofo sempre fora tratado como persona non grata, pode ser o título dado à matéria publicada no jornal Der Alemanne, a respeito do sucessor de Heidegger no cargo de reitor. O texto dizia: "O primeiro reitor nacional-socialista da Universidade" - o que, de maneira contundente, serve como endosso à tese de que o "mal-entendido político-prático" resultou numa mancha dificilmente esquecida na biografia daquele que certamente pode ser mencionado como um dos principais autores do século XX. Conforme suas próprias palavras, a princípio Heidegger acreditara que a partir do "diálogo com o nacional-socialismo poderia ser aberto um caminho novo, o único possível, para uma renovação" ${ }^{9}$. Por renovação, tinha em vista que a "Universidade devia outra vez renovar-se a partir de sua própria reflexão e alcançar, assim, uma posição firme frente ao perigo de uma politização da ciência"10. Isso é o que também está presente no discurso inaugural de seu mandato como reitor em Freiburg, nomeado A autoafirmação da universidade alemã - um texto que é apontado como importante prova por aqueles que afirmam o nazismo compulsório de Heidegger.

Nas palavras do filho mais velho de Heidegger, Hermann Heidegger, que prefaciou o volume celebrativo publicado em 1988, reunindo tanto o discurso reitoral, acrescido de um breve comentário retrospectivo do filósofo sobre os seus dez meses de reitor, quanto o texto da entrevista ao Der Spiegel, seu pai "nunca negou seu passageiro compromisso com aquele movimento. Sem dúvida, durante o tempo de seu reitorado, também cometeu falhas. Algumas deficiências nunca desmentiu. Mas não foi nenhum colaborador acrítico, nem ativo, do movimento do partido"11.

\footnotetext{
${ }^{8}$ HEIDEGGER, Martin. "Gespräch mit Martin Heidegger am 23. September 1966“. In. Der Spiegel, n. 23, 1976. p. 204.

9 HEIDEGGER, Martin. "Gespräch mit Martin Heidegger am 23. September 1966“. In. Der Spiegel, n. 23, 1976. p. 198.

${ }^{10}$ HEIDEGGER, Martin. „Gespräch mit Martin Heidegger am 23. September 1966“. In. Der Spiegel, n. 23, 1976. p. 198.

${ }^{11}$ In. G. NESKE u. E. KETTERING, Hg., Antwort. Martin Heidegger im Gespräch, Pfullingen, Neske, 1988.
} 


\section{§ 3. Algumas reações em defesa da integridade da filosofia heideggeriana}

Reações no âmbito da filosofia e em defesa da integridade do pensamento de Heidegger, a despeito da eventualidade histórica representada por sua aproximação ao Partido Nacional Socialista, também não custaram a aparecer. Nesse sentido, podemos citar o nome de François Fediér ${ }^{12}$, na França, mas, sobretudo, a cooperação entre o professor Friedrich-Wilhelm von Herrmann, emérito da Universidade de Freiburg e coordenador, conforme testamento deixado por Heidegger, da edição de sua obra completa, e Francesco Alfieri, da Universidade Lateranense de Roma. Através de um rigoroso estudo dos manuscritos que integram os Schwarze Hefte, especialmente das passagens referidas por Trawny a respeito do nazismo onto-histórico presente ao pensamento heideggeriano, Alfieri e von Herrmann desconstruíram um a um os argumentos suscitados, evidenciando o real sentido dos conceitos e passagens, caso tomados adequadamente no curso de suas aparições. O livro resultado desse esforço já se encontra reeditado nas principais línguas modernas e em breve também estará disponível no Brasil, com o título Martin Heidegger: la veritá sui Quaderni $n e r i^{13}$. Além do testemunho de von Herrmann e das análises realizadas por Alfieri (que ocupam a maior parte do volume), o texto também conta com quadros comparativos, com fotografias das páginas originais do texto heideggeriano, e com a contribuição de alguns outros estudiosos e jornalistas dedicados ao assunto. A partir de sua leitura, resta clara que a guinada crítica de Heidegger não deixou de fora a sua decepção com o que havia se projetado como a esperança de uma Alemanha novamente liberta. Assim, Hitler e sua ideologia são incluídos no rol dos equívocos praticados pelo Ocidente na busca pelo seu caminho, um caminho que cada vez mais afastou-se de um pensamento capaz de lançar-se ao profundo.

Para que essa discussão, porém, não se esvaeça na simples divisão entre dois grupos, o dos prós e o dos contra Heidegger, recentemente tive acesso a uma coletânea de páginas manuscritas que novamente chamaram minha atenção a respeito desse tema. Por ora tendo como base o esforço de um jovem letão, cuja contribuição anônima pode ter cooperado na consecução de um bom desfecho para "o caso Heidegger".

Após a Segunda Guerra Mundial, as forças de coalisão estabeleceram um rigoroso procedimento, o qual chamaram "denazificação". Sua implementação ficou a cargo dos franceses, submetendo à investigação todos aqueles que de algum modo tiveram ligação com o partido nazista. Professores, médicos,

\footnotetext{
${ }^{12}$ E existe uma edição brasileira para o texto referido: cf. FÉDIER, François. Heidegger: anatomia de um escândalo. Tradução de Orlando dos Reis. Petrópolis, RJ: Vozes, 1989.

${ }^{13}$ Cf. ALFIERI, Francesco; von HERRMANN, Friedrich-Wilhelm. Martin Heidegger: la veritá sui Quaderni neri. Brescia: Editrice Morceliana, 2016.
} 
funcionários públicos, todos tinham sua vida e sua produção investigadas a fim de se verificar o seu maior ou menor teor de periculosidade, isto é, de manutenção da ideologia antissemita. Esse foi o caso de Heidegger, que a partir de 1946 teve o seu mandato docente cassado, estando suspenso de suas atividades na Universidade de Freiburg enquanto durasse o processo. Existem relatos desse período, extraídos de cartas trocadas entre Martin Heidegger e seu irmão, Fritz Heidegger, em que o filósofo descreve o sofrimento imputado pela desconfiança presente em olhares e murmúrios de todos os que o cercavam, como o que segue: "Caro Fritz! [...] Você tem razão. O meu nome é uma questão política, de um modo ou de outro. Todos falam de mim e ninguém reflete - exceto os poucos que permanecem em silêncio. Nos alemães prevalece uma terrível condenação"14. Justamente nessa fase de sua vida Heidegger adota a cabana em Todtnauberg como residência oficial, dedicando-se ali ao pensar de maneira ainda mais radical. É esse o período em que descobrimos uma relação inesperada.

\section{$\S 4$. O jovem letão apátrida e o pensador da fronteira do ser}

Como dizia de início, para mim é realmente surpreendente como na vida episódios tão distantes podem interagir. Esse é o sentimento que tive, como pesquisador parcialmente dedicado à compreensão da obra de Heidegger, ao me deparar - quase que por puro acaso - com o relato de Janis Roze em sua autobiografia. Como um dos pesquisadores agraciados com o título doctor honoris causa da Pontifícia Universidade Católica de Goiás, instituição em que atuo, o professor Roze fora convidado a publicar suas lembranças; lembranças de uma longa vida, hoje já na iminência de completar 95 anos de história. Tendo como título O corredor da vida de Janis Roze, foi-me pedido contribuir com a revisão do texto, organizado e traduzido pelo professor Clóvis Ecco. O material tem previsão de lançamento ainda em 2021. Eis, então, o contexto que me levou à leitura de seus manuscritos e, entre as várias páginas, destacar o seu envolvimento com o "caso Heidegger", que passo a descrever.

No contexto de uma Alemanha desolada, destaca-se a figura de um jovem letão, afastado de sua terra natal por conta da reocupação da União Soviética. Sozinho, sem perspectivas e sem a possibilidade de retornar à sua família, Janis Arnold Roze resolveu alistar-se como cooperador das forças francesas, que ocupavam o sul alemão. $O$ exército francês precisava de alguns funcionários para trabalhar em seu governo militar, que provisoriamente administrava a zona ocupada. Entre outras atribuições, cabia a esses funcionários inspecionar os documentos e demais arquivos que

${ }^{14}$ Cf. ALFIERI, Francesco; von HERRMANN, Friedrich-Wilhelm (Orgs.). Martin Heidegger Fritz Heidegger - Carteggio - 1930-1949. Brescia: Editrice Morceliana, 2018. p. 150. 
compunham os dossiês de denazificação. Lembra Roze: “Todas as manhãs eu recebia um pacote de pastas sobre alemães que estavam mais ou menos envolvidos com os nazistas. Eles continham informações e documentos em alemão sobre suas atividades. Eu os lia e depois opinava se eles eram apenas pequenos peixes ou se haviam se envolvido significativamente com os ideais e atividades nazistas". É verdade que as principais figuras envoltas na ideologia do nazismo já se encontravam sob julgamento no tribunal de Nuremberg. Casos menos significativos, no entanto, permaneciam sob a responsabilidade dos comitês de denazificação.

Mas o que haveria entre o trabalho desenvolvido pelo jovem letão expatriado e o "caso Heidegger"? A resposta para essa questão é oferecida numa das passagens descritas pelo professor Janis Roze nos manuscritos com os quais tive contato: "Um dia, recebi um novo pacote de arquivos nazistas. Abrindo, eu quase congelei. Na minha mesa estava o dossiê de ninguém menos que Martin Heidegger, o grande filósofo alemão. De alguma forma, minhas rodas internas começaram a girar, como se tentassem lidar com algo quase incompreensível. Eu, um Senhor Ninguém, um refugiado da Letônia, sem país e sem nada, tive que decidir sobre o futuro de um dos grandes pensadores do século $X X^{\prime \prime}$. Notadamente, a resolução do inquérito que tratava o envolvimento de Heidegger com o Nacional Socialismo não se deu unicamente pela intervenção do jovem estrangeiro. Como sabemos por outras vias históricas, no andamento do processo houve avanços e reveses, o testemunho de pessoas ligadas a Heidegger, a atestação de periculosidade por parte de profissionais da psiquiatria, enfim, um arrolado de idas e vindas que acabaram por retirar quaisquer tentativas de imputabilidade legal. Contudo, também não se pode deixar de reconhecer a discreta $e$ até muito pouco tempo desconhecida contribuição operada por Janis Roze, em sua confluência de caminhos com o caminho do filósofo da fronteira do ser. Nesse sentido, como mote para rediscutir a questão política de Heidegger, essa breve nota quer também cooperar na publicidade dessa relação, com marcas profundas na história do hoje emérito professor Janis Roze.

Ao ler o dossiê de Heidegger, diz Roze, "ficou claro que essa mente poderosa estava bastante confusa em seus relacionamentos humanos e em sua posição política". Uma aproximação tão forte entre o filósofo e o nazismo foi para o jovem letão motivo de espanto, mas também de compreensão e de reconhecimento de que não havia ali elementos suficientes para uma condenação. Como resolução, recomendou-se que a classificação nazista de Heidegger fosse rebaixada para uma estratificação inferior ao indicado no dossiê, cooperando, quem sabe, com o encerramento do inquérito. São, contudo, as palavras finais da recordação que mais chamam a atenção. Diz Roze: "Penso que Heidegger nunca soube que um refugiado letão sem rosto lhe ofereceu uma mão de ajuda e perdão. Parece estranho, não é?". De fato, as orientações compostas pela vida são sempre surpreendentes, e não se pode dizer com segurança que o desfecho do "caso Heidegger" 
seria diferente sem a intervenção do agente outrora sem rosto que aqui desvelamos, passados pouco mais de setenta anos desde a ocorrência.

\section{$\S 5$. Algumas repercussões da descoberta realizada}

Com base no que descobri e na possibilidade de dar alguma visibilidade ao relatado por Janis Roze em suas memórias, quis fazer conhecer à família de Heidegger o papel desempenhado pelo forasteiro até então desconhecido. Para isso, contei com a ajuda do prof. Friedrich-Wilhelm von Herrmann, com quem nos últimos anos estabeleci frequente contato por correspondência. Embora a família Heidegger tenha expressado solicitude ante o relatado, a manifestação de von Herrmann deixa claro que o debate sobre qualquer forma de nazismo inerente à biografia do filósofo é ainda motivo de mal-estar. Isso porque entre aqueles pertencentes ao círculo de convivência mais próxima a Heidegger (e von Herrmann é, certamente, um dos referenciais ainda vivos) prevalece a convicção de que, para além de um infortúnio em seu itinerário, o pensamento de Heidegger é incompatível com toda forma de especulação a respeito de seu compromisso com orientações nazistas e/ou antissemitas. Sobre isso, vale a pena mencionar as palavras de von Herrmann em correspondência a mim remetida em 08 de setembro de 2020: "Caro prof. Martins Filho, a atitude do letão é realmente estimável. Mas ao longo do tempo acusações como essa provaram-se falsas. No volume 16 da Gesamtausgabe podem ser lidos todos os documentos dessa época. O filho de Heidegger, Dr. Herrmann Heidegger, historiador, sabia muito bem que seu pai foi o único reitor no nazismo que não proibiu livros nem saudou com 'heil Hitler'. Ao contrário, deixou sua posição já após um ano, porque estava convicto de que o nazismo seria uma catástrofe". De fato, foram muitos os alemães que, como Heidegger, viram-se seduzidos pela proposta nacional-socialista, especialmente nos anos imediatamente anteriores a sua ascensão ao poder. Ocorre que, como está abundantemente indicado nos Schwarze Hefte, não foi preciso muito tempo para perceber a inclinação nociva da política conduzida por Hitler - mesmo que o estrago biográfico, no caso de Heidegger, já estivesse feito.

Para von Herrmann, que desde 1975 coordena a edição das obras completas de Heidegger, a querela reacendida nos últimos anos deve ser lida como uma espécie de engodo, isto é, como a tentativa de autopromoção a partir de um tema ainda bastante sensível, especialmente aos alemães. Como há base histórica para fomentar o debate, acusações pautadas por interpretações desconexas grassam como critério interpretativo legítimo. Além disso, um segundo problema considerado crucial para von Herrmann é o fato de que um editor acompanhe sua própria edição com um livro difamatório contra o pensador que edita. Também em correspondência, dessa vez de 09 de setembro de 2020, o professor emérito reage da seguinte maneira: "A verdade é que 
Heidegger disse como um testamento que nenhum editor da Gesamtausgabe seria autorizado a dizer sua própria ideia junto ao Nachwort, nem a acompanhar seu volume editado com um livro com suas próprias ideias de filosofia". A questão é que ao suscitar desconfianças sobre a obra de Heidegger, von Herrmann sente-se frontalmente atingido em seu trabalho de mais de cinco décadas dedicadas à sua compreensão. Eis porque também nos partilhou e permitiu a veiculação do pronunciamento que realizou no lançamento do livro Martin Heidegger: la veritá sui Quaderni neri, na Universidade de Pavia, Itália, em 2016, o qual transcrevemos: "Nessa solene circunstância, e antes de apresentar minha conferência, quero fazer uma declaração: o que concretamente significam o antissemitismo e o nazismo, aprendi e experimentei na minha infância. Vivi em Potsdam, próxima a Berlim, onde meu pai era pastor de uma paróquia evangélica luterana, crítica ao regime: as orações dominicais do meu pai eram controladas pela Gestapo. Em seguida, durante a ditadura socialista da DDR, o mesmo tipo de vigilância estatal se repetiu, operado pelo Serviço de Segurança Nacional. Por sessenta anos me ocupo da obra de Martin Heidegger, que agora conheço perfeitamente em toda a sua inteireza. Se no curso de minha longa e frequente visita aos escritos de Heidegger descobrisse qualquer traço ou elemento racista, antissemita ou nacional-socialista, não teria jamais dedicado minha vida acadêmica à interpretação e ao comentário da obra desse pensador". Nessa oportunidade, faço questão de mencionar as palavras de von Herrmann integralmente, tanto por respeito ao posicionamento de alguém que considero como fundamental para a pesquisa da obra de Heidegger, quanto por serem relativamente inéditas aos leitores brasileiros. São, como se vê, não apenas a adoção de uma postura por conveniência, mas a partilha de um extrato de vida, a convicção de quem diretamente se viu e se vê relacionado à questão, e que também a pôde contemplar desde um olhar de proximidade, sentindo o tema "na própria pele", experimentando-o em sua vida pessoal e familiar.

Em se tratando do contexto atual da academia alemã, e mesmo dos centros de estudo especializados no pensamento heideggeriano, a postura adotada por von Herrmann não é, porém, a única, e, nem mesmo, a predominante. $\mathrm{O}$ assunto causa ainda muita divisão, com interpretações que variam desde a completa recusa da filosofia de Heidegger até a imposição de um limite entre o que representou a sua produção em comparação com sua vida. Günter Figal, ex-presidente da Martin-Heidegger-Gesellschaft, declarou em entrevista que a influência antissemita em Heidegger, embora não possa ser admitida em sua filosofia, manteve-se de alguma forma incrustada em sua vida e posicionamentos morais ${ }^{15}$. Para Figal, trata-se de um terrível desgosto, o que o levou a renunciar ao cargo de presidente da associação dedicada ao estudo do pensador, embora ainda reconhecendo impossível pensar a filosofia no

${ }^{15}$ Intervista. Günter Figal: Disgustose e terribili quelle frasi del mio Heidegger. In. Antiper, marzo $18,2014$. 
século XX sem atravessar Heidegger. Como dizia anteriormente, a brecha histórica, unida à personalidade difícil de Heidegger (como apontam os que com ele conviveram) e, ainda, a uma vida bastante movimentada quanto a alguns aspectos morais considerados como tabu, tornam o "caso Heidegger" suscetível a especulações de toda natureza. Isso além de que, especialmente entre os alemães, seja em qual nível for, toda forma de intolerância, preconceito ou discriminação são hoje completamente inadmissíveis, de forma que cada vez menos se considera a produção teórica de alguém, sobretudo no campo da filosofia, deslocada de sua relação com a vida prática, com as posturas e posicionamentos em nível pessoal.

\section{§ 6. Como encerrar um debate sem fim?}

Mas como encerrar um debate que parece não ter fim? Em primeiro lugar, tal pergunta é, notadamente, retórica. Com Heidegger aprendemos que todo o movimento de compreensão da nossa condição histórica se dá num horizonte temporal necessariamente finito. $\mathrm{O}$ mesmo se aplica para o desenvolvimento de qualquer questão, que sempre terá a finitude como limite para o seu desenvolvimento. De minha parte, quanto à questão política de Heidegger, penso que se trata de uma situação bastante complexa, que deve ser vislumbrada a partir de diferentes prismas. $\mathrm{O}$ entendimento da situação política da Alemanha na década de 1930 exige um olhar multicêntrico, que tome em conta diversos fatores em ordem conjuntural. $\mathrm{O}$ que não dizer quando esse emaranhado de situações se cruza com uma das personalidades mais relevantes do século? A filosofia de Heidegger deixou marcas profundas em todo o horizonte conceitual do século XX e, por isso, não pode ser simplesmente ignorada ou, pior, desprezada em função de episódios esparsos de sua vida. Se é verdade, como diz o ditado, que a boa árvore se mede pelos frutos, é inegável a fertilidade inerente à obra de Heidegger nos mais variados setores, fazendo com que a nocividade querida por alguns seja completamente dissipada em favor de uma colheita farta. Mesmo Janis Arnold Roze, a referência que me despertou à escrita deste texto, soube reconhecer que estava diante de uma das inteligências mais peculiares de sua época. Deu, por isso, sua contribuição discreta, alardeando o ocorrido somente após terem se passado mais de sete décadas. Em nosso caso, mais que mera descrição historiográfica, fez-se oportunidade para retomarmos a questão política de Heidegger, que, como tal, permanecerá aberta a novas provocações. 